\section{Pain and Emotional Status}

\section{To the Editor:}

In a recent interesting article Manchikanti et al (1) demonstrated that there was a significant difference in the frequency of depressive disorders (major depression and dysthymia) between controls (no pain) and two groups of chronic pain patients (CPPs): pain one region only and pain more than one region. Measurements for the presence of depressive disorders was obtained from the MCMI-III (1).

As the authors point out, previous researchers have reported a greater prevalence of mood disorders in CPPs with widespread pain (2) and two or more pain complaints (3) versus controls. The authors' results support these previous results. However, at issue is why this should occur?

In a recent evidence-based structured review (not a meta analysis), Fishbain et al (4) were able to address these questions. Here, it was clearly shown that: 1) depression is more common in chronic pain patients than controls; 2) the preponderance of the evidence indicated that depression followed the development of chronic pain; 3) however, depression predisposition predisposed to the development of depression following the development of chronic pain; 4) and most important, there was a relationship between the perceived severity and frequency of pain and development of depression. This last study was recently supported by a meta analysis performed on studies utilizing rheumatoid arthritis patients who were depressed and had pain (5). Here, effect sizes for depression were shown to vary in a linear manner in proportion to the effect size for pain. The authors concluded that depression is more common in rheumatoid arthritis patients than in healthy individuals due in part to the levels of pain experienced (5). Thus, pain can service an etiological function in the development of mood disorders in CPPs. As such, studies such as that of Manchikanti et al (1) are difficult to interpret unless there is some control for pain level. It is likely that if such controls had been utilized in this study that it would have been found that there was a significant difference in pain levels between the CPPs with pain in one region versus those CPPs with pain in multiple regions.

\section{REFERENCES}

1. Manchikanti L, Pampati V, Beyer C et al. Do number of pain conditions influence emotional status? Pain Physician 2002; 5:200-205.

2. Benjamin S, Morris S, McBeth J et al. The association between chronic widespread pain and mental disorder. Arthritis Rheum 2000; 43:561-567.

3. Dworkin SF, Von Korff M, LeResche L. Multiple pains and psychiatric disturbance: An epidemiologic investigation. Arch Gen Psychiatry 1990; 47:239-244.

4. Fishbain DA, Cutler R, Rosomoff HL et al. Chronic pain associated depression: Antecedent or consequence of chronic pain? Clin J Pain 1997; 13:116-137.

5. Dickens C, McGowan L, Clark-Carter B et al. Depression in rheumatoid arthritis: A systematic review of the literature with a meta-analysis. Psychosomatic Med 2000; 64:52-60.

David Fishbain, MD, FAPA

Professor Psychiatry \& Neurological Surgery and Anesthesiology

University of Miami School of Medicine

University of Miami Comprehensive Pain and Rehabilitation Center 